Revista de la red interuniversitaria de estudios sobre las literaturas rioplatenses contemporáneas en Francia

$8 \mid 2013$

Argentina y Uruguay: lecturas del país vecino en la literatura rioplatense contemporánea (siglos XX y XXI)

\title{
El Uruguay de Borges : un justo vaivén de la aproximación y de la distancia
}

Graciela Villanueva

\section{OpenEdition}

\section{Journals}

Edición electrónica

URL: http://journals.openedition.org/lirico/907

DOI: $10.4000 /$ lirico.907

ISSN: 2262-8339

Editor

Réseau interuniversitaire d'étude des littératures contemporaines du Río de la Plata

Referencia electrónica

Graciela Villanueva, «El Uruguay de Borges : un justo vaivén de la aproximación y de la distancia », Cuadernos LIRICO [En línea], 8 | 2013, Puesto en línea el 01 enero 2013, consultado el 19 abril 2019. URL : http://journals.openedition.org/lirico/907 ; DOI : 10.4000/lirico.907

Este documento fue generado automáticamente el 19 abril 2019.

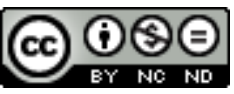

Cuadernos LIRICO está distribuido bajo una Licencia Creative Commons Atribución-NoComercialSinDerivar 4.0 Internacional. 


\title{
El Uruguay de Borges : un justo vaivén de la aproximación y de la distancia
}

\author{
Graciela Villanueva
}

1 Muchos críticos y muchos lectores han señalado la importancia y el afecto que Jorge Luis Borges manifestó siempre por el Uruguay y por los uruguayos, a quienes solía referirse, a la antigua usanza, diciendo « los orientales ». Por citar sólo algunos ejemplos de trabajos que estudian la presencia del Uruguay en la producción de Borges, recordemos el de Rodríguez Monegal, de 1982, acerca de la visión borgeana del ultraísmo uruguayo ${ }^{1}$, o el de Daniel Balderston, de 2000, donde se analizan los sentidos que en la obra de Borges tiene la frontera norte de la región cultural del Plata (Uruguay y sur de Brasil), un aspecto menos estudiado que la visión simbólica de lo que el autor de Ficciones definió como «el sur $»^{2}$. En una fecha mucho más reciente (agosto de 2012), en un artículo publicado en el semanario uruguayo Brecha acerca de la idealización persistente del Uruguay en el imaginario argentino, Carolina Porley cita el análisis publicado en 1999, en ese mismo semanario, por Ana Inés Larre Borges, bajo el título " Memoria oriental de Borges », un trabajo que demuestra que la obra de este escritor suele presentar al Uruguay como un lugar de refugio de los argentinos frente a la barbarie ${ }^{3}$.

2 El objetivo de nuestro trabajo es cartografiar el Uruguay en la obra de Borges y mostrar cómo a lo largo del tiempo los mapas de la otra orilla que el escritor argentino dibuja van variando ligeramente.

\section{Entre las dos orillas de un turbio y lento río}

3 Empecemos por la Autobiografía de Borges (1970)4. La referencia al Uruguay es allí discreta pero importante. La otra orilla del Plata aparece, en efecto, en las primeras líneas :

No puedo precisar si mis primeros recuerdos se remontan a la orilla oriental $u$ occidental del turbio y lento Río de la Plata : si me vienen de Montevideo, donde pasábamos largas y ociosas vacaciones en la quinta de mi tío Francisco Haedo, o de Buenos Aires. ${ }^{5}$ 
Cabe recordar que así como hubo guerreros en los dos linajes de Borges, también hubo uruguayos tanto en la línea materna como en la línea paterna de su genealogía. Uruguayos fueron la abuela materna de Borges (Leonor Suárez Haedo), su propia madre (Leonor Acevedo Suárez) y también su tío y sus primos Haedo, con quienes Borges compartió las vacaciones de su infancia ; uruguayo fue también su abuelo paterno (el coronel Francisco Borges Lafinur). Y en el origen de este cruce de orillas encontramos siempre la misma historia : el exilio -el del abuelo materno de Borges, el de su bisabuelo criollo por línea paterna- para escapar al régimen de Rosas.

Para mostrar el afecto de Borges por los orientales, recordemos que así como Jorge Borges (el padre del escritor) se complacía en repetirle a Fanny Haslan que aunque él hubiera nacido en la provincia de Entre Ríos, lo que realmente importaba era que había sido « engendrado en la pampa " ${ }^{6}$, Jorge Luis solía repetir públicamente que él era un poco uruguayo porque había sido concebido en el departamento de Paysandú 7 .

6 Sean cuales fueren las hipótesis (incomprobables) acerca del lugar en que Jorge Luis Borges fue concebido, lo cierto es que las referencias al Uruguay y a su gente aparecen con frecuencia en sus ensayos, en su poesía y en sus cuentos. El análisis de estas referencias, centrales en ciertos textos, otras veces puntuales y muy a menudo oblicuas, revela una serie de matices sobre los que vale la pena volver.

7 En su epílogo a la Antología de la moderna poesía uruguaya $(1900-1927)^{8}$, Borges evoca el recuerdo de " una siesta, un olor a tierra mojada, una luz distinta » y subraya la sutil diferencia entre argentinos y uruguayos, tan parecidos pero tan leve y misteriosamente diversos. Es importante observar que, repitiendo el gesto de muchos otros, Borges parece identificar a los argentinos con los porteños o, como mucho, con los habitantes de la llanura pampeana. El escritor define su propia actitud respecto de los uruguayos como la de toda amistad y todo amor : « un justo vaivén de la aproximación y de la distancia ». Y es la palabra "vaivén » la que importa destacar aquí, ya que la visión de la otra orilla oscila a lo largo de toda la obra de Borges entre el borramiento y la insistencia (en tono menor es cierto, pero insistencia al fin) en la sutil distancia que separa a los orientales de los argentinos.

\section{El criollismo : un « silencio arrimado al fatalismo » de ambos lados del Plata}

En 1925, en « Queja de un criollo » (Inquisiciones) Borges se esfuerza por refutar una visión equivocada del criollismo y al hacerlo no establece diferencias entre una y otra ribera del río. Aparicio Saravia es en este sentido semejante a Facundo Quiroga "yendo a una acechanza de inevitables y certeros puñales » o al general San Martín " desapareciéndose en Guayaquil ». Entre los rasgos característicos del criollismo de las dos orillas están menos presentes la vehemencia y el énfasis que el fatalismo, el desgano, la sencillez, el apego a lo conocido y una indiscutible desconfianza por lo urbano y lo moderno. Así es el alma criolla uruguaya y argentina, o así era, ya que Borges sabe que esta idiosincracia pervive en cierta tradición, pero que no es inmune al paso de los años. Ése fue en todo caso el criollismo de José Hernández y de William Hudson, los dos escritores que registraron los actos iniciales de la "tragedia criolla " provocada por la llegada de los gringos y la instalación de alambrados en la pampa. Y Borges ubica en las antípodas de esa sencillez criolla al patrioterismo de Rojas y al gongorismo de Lugones. 
9 Un año después de la "Queja de un criollo », la obra de Hudson vuelve a estimular la reflexión de Borges. Pero mientras que en « Queja de un criollo » Hernández y Hudson eran igualmente valorados, en «La tierra cárdena " (El tamaño de mi esperanza, 1926) Borges pone The Purple Land por encima de Martín Fierro. Aunque Hudson escriba en inglés, argumenta Borges, su expresión es la del « criollo litoraleño, criollo en bondá [sic] y en sorna », criollo que frente a la " gritona » dicotomía sarmientina, no vacila en elegir « sin melindres » la barbarie y que logra así oponerse firmemente a quienes quieren hacernos creer que los malevos de la Mazorca fueron «los únicos encarnadores de la criollez ». Borges piensa que Hudson se mantiene fiel al espíritu del criollismo a lo largo de toda su obra y lamenta que el final del Martín Fierro caiga, en cambio, en la « palinodia desdichadísima » y el « puro sarmientismo ».

10 Los mismos criollos entonces en las dos orillas del Plata, y si algo los distingue, ese algo parece ser la seguridad uruguaya, actitud de quien sabe que no necesita gritar para imponerse.

\section{Un matiz no menos importante que el color : el sentir dramático de la poesía uruguaya}

11 El primer acto del vaivén entre la aproximación y la distancia no tarda en llegar, como lo demuestra la lectura de otros ensayos de aquellos mismos años, ensayos que presentan la leve brecha que separa a argentinos y uruguayos en términos diferentes y en algún sentido opuestos a los que acabamos de observar. En efecto, si en la « Queja de un criollo » (1925) y en «La tierra cárdena » (1926) Borges insistía en la figura del criollo oriental sereno y sin melindres, el punto de vista varía en cambio en « Reverencia del árbol en la otra banda » (1926), ensayo en el cual el uruguayo aparece como un ser vehemente, dramático y belicoso. Sin negar que se trata simplemente de un matiz (« el criollismo a todos nos junta, pero el matiz no es menos real que el color»), Borges acentúa las diferencias entre los dos márgenes del Plata. El oriental -dice- nace « a la vera de hondos árboles y de largas cuchillas» y se instala en "quintas y ceibales » y esto explica la tendencia de la poesía uruguaya a « un sentir dramático de conflicto de ramas que se atraviesan como voluntades », sentir opuesto al de la poesía porteña, « cuyos ejemplares y símbolos fueron siempre el patio y la pampa, arquetipos de rectitud ».

12 La misma idea se repite un año más tarde en el epílogo ya citado a la antología de poesía uruguaya de Pereda Valdés (1927). Los orientales -dice Borges- se mueven en un paisaje " de cuchillas y arboledas, cuando no de agua larga », mientras que la poesía porteña sólo vislumbra un horizonte de tierra, « la pampa o su inauguración, el suburbio ». El agua de los uruguayos « induce una vehemencia de ola en sus versos » y el bosque les « enseña su sentir dramático de conflicto, de ramas que se atraviesan como voluntades", inclinándolos a la " petición vistosa ». Los uruguayos -dice Borges- son belicosos y serios, mientras los «hombres de pampa y de derechas calles» son («somos» dice Borges) haraganes y frecuentemente irónicos (Borges, « Palabras finales », 1927).

13 Borges concluye su epílogo a la antología de Pereda Valdés con una reflexión que los uruguayos suelen citar :

Los argentinos vivimos en la haragana seguridad de ser de un gran país, de un país cuyo solo exceso territorial podría evidenciarnos, cuando no la prole de sus toros y la feracidad alimenticia de su llanura. Si la lluvia providencial y el gringo providencial no nos fallan, seremos la Villa Chicago de este planeta y aun su 
panadería. Los orientales, no. De ahí su claro que heroica voluntad de diferenciarse [sic], su tesón de ser ellos, su alma buscadora y madrugadora. Si muchas veces, encima de buscadora fue encontradora, es ruin envidiarlos. El sol, por las mañanas, suele pasar por San Felipe de Montevideo antes que por aquí.

El porvenir parece reservarles a los argentinos el previsible -aburrido y trivial- puesto de guardianes del granero del mundo o, como mucho, un empleo como panaderos del orbe. La modesta pequeñez de los uruguayos parece en cambio augurarles imprevisibles y felices encuentros.

En un apartado que recuerda el interés de Borges por la poesía uruguaya, no podemos dejar de citar los artículos dedicados al tema en Inquisiciones (1925) y en El tamaño de mi esperanza (1926). No sólo sobre Hudson escribe Borges en Inquisiciones; también dedica ensayos a la poesía de Pedro Leandro Ipuche (« la criolledad en Ipuche »), a la poesía de Fernán Silva Valdés («Interpretación de Silva Valdés ») y a la poesía de Julio Herrera y Reissig («Herrera y Reissig») y, en El tamaño de mi esperanza, a Poemas nativos de Silva Valdés (" El otro libro de Fernán Silva Valdés »). Borges destaca en Ipuche « la criolledad [que] se refleja en cada yuyito ", « los festivos rostros de la humana amistad » $\mathrm{y}$ « la gran luna de la cavilación solitaria ». En el ensayo consagrado a Silva Valdés en 1925, Borges destaca la sutil manera en que el poeta reutiliza las imágenes tradicionales: "Las imágenes son nuevas, el compás es inusitado [...] y sin embargo yo aseguraría que no es el principio de un arte inédito, sino la cristalización y casi la perdición de otro antiguo ». Y en 1926 Borges insiste en la manera en que están escritos los Poemas nativos de Silva Valdés, "medio como quien canta y medio como quien habla y y observa cómo «la indecisión de ambas formas", expresándose "como los payadores antiguos en la pelea melodiosa del contrapunto, nos dice su visión del campo oriental ». La lectura borgeana de Herrera y Reissig vuelve sobre este juego de tradición y ruptura: «[Herrera] supo templar la novedad, ungiendo lo áspero de toda innovación con la ternura de palabras dóciles y ritmo consabido. Lo antiguo en él pareció airoso ».

Para concluir con el análisis de la presencia de la poesía uruguaya en la obra de Borges, es indispensable recordar que tanto en el caso del tango como en el caso de la poesía gauchesca, Borges afirma que es probable que los orígenes sean uruguayos. Al tango se refiere en una estrofa de su « Milonga para los orientales » (Para las seis cuerdas, 1965):

Milonga del primer tango

Que se quebró, nos da igual,

En las casas de Junín

0 en las casas de Yerbal.

En el caso de la gauchesca, además de afirmar que es probable que haya nacido al este del Plata, Borges sostiene que es en Uruguay donde surgen las últimas grandes obras del género :

La poesía gauchesca que acaso se inició en el Uruguay con las trovas de Hidalgo y que después erró gloriosamente por nuestra margen del río con Ascasubi, Estanislao del Campo, Hernández y Obligado, cierra hoy su gran órbita con las voces de Pedro leandro Ipuche y de Silva Valdés. (« Ascasubi », en Inquisiciones, 1925)

\section{Un Uruguay más elemental y más bravo}

El matiz que distingue los dos márgenes del Plata en algunos cuentos de Borges prolonga de algún modo la idea formulada en « Reverencia del árbol en la otra banda » (1926), pero en lugar de insistir en el dramatismo de los orientales, subraya su bravura : « el Uruguay - 
dice el narrador de «La otra muerte » (1949) - es más elemental y más bravo que nuestro país » y enseguida insiste en la supuesta, implícita y eterna rivalidad entre los uruguayos y los argentinos : « Damián, como gaucho, tenía la obligación de ser Martín Fierro - sobre todo ante gauchos orientales ». La supuesta rivalidad entre los habitantes de ambas orillas contribuye a explicar que para el entrerriano fuera tan importante demostrar su valentía, aunque más no fuera a posteriori, y que consagrara las décadas que le quedaron de vida después de la derrota de Masoller a « corregir su muerte ».

Algo similar plantea el cuento «Avelino Arredondo » (en El libro de arena, 1975), en el que Borges recrea la figura del personaje histórico que asesinó el 25 de agosto de 1897 al presidente uruguayo Juan Bautista Idiarte Borda ${ }^{9}$. Idiarte Borda era un líder del partido colorado y Avelino Arredondo también adhería a ese partido, pero pensaba que el presidente estaba traicionando los ideales de su gente. Jorge Luis Borges respeta la identidad política del Arredondo real, por eso crea un personaje que en la escena final del cuento elige ponerse « una corbata colorada » y que en el momento de entregarse a las autoridades declara :

- Soy colorado y lo digo con todo orgullo. He dado muerte al Presidente, que traicionaba y mancillaba a nuestro partido.

El uruguayo aparece definido aquí como el hombre que no acepta las medias tintas, un hombre que es de alguna manera, como decía el narrador de «La otra muerte », " más elemental y más bravo ", más principista que el argentino y más seguro de sí mismo. En este sentido podría decirse, contradiciendo otras imágenes anteriores asociadas al Uruguay, que el oriental no necesita la vehemencia ni el dramatismo y que, si estos comportamientos aparecen, es simplemente porque el uruguayo cree profundamente en lo que hace y en lo que es.

21 Recordemos que en una serie de diálogos de Borges con Sábato registrados entre diciembre de 1974 y marzo de 1975 por el periodista Orlando Barone, Borges insistía en esta apacible seguridad oriental y la contraponía a cierta tendencia de los argentinos, propia del pasado (y muy sensata según Borges), a dudar de sí mismos :

- Borges: Enrique Amorim, que era oriental, cuando algo andaba mal decía:

«Uruguayo y basta ». Y aquí cuando chico se solía decir: "Más criollo que el olor feo ». Ahora no se diría eso ¿no? En aquel tiempo parece que el país era más sensato... Había un negocio en la Avenida de Mayo con un cartelito que aseguraba : «Argentino, pero bueno ». ${ }^{10}$

\section{El tiempo anchísimo que los relojes no picanean}

Hay otro matiz de la imagen de Uruguay que se repite varias veces en la obra de Borges y que tiene que ver con la manera en que, según el argentino, pasa el tiempo del otro lado del río. En « La tierra cárdena » (1926), Borges observaba que Hudson sabía pintar la tierra del « tiempo anchísimo que nunca picanearon los relojes y que midieron despacito los mates».

Borges suele, en efecto, presentar al Uruguay como una tierra capaz de hacerle jugarretas al tiempo. Dos versos expresan este rasgo en el poema «Montevideo » (de Luna de enfrente, 1925) :

Eres el Buenos Aires que tuvimos, el que en los años se alejó quietamente.

$[\ldots]$

Puerta falsa en el tiempo, tus calles miran al pasado más leve. 

verificarse la tendencia ya señalada a borrar las diferencias Plata. Es lo que sucede en los relatos que cuentan una y otra vez, con nombres distintos, pero repitiendo los hechos centrales y muchos de los matices, la infinita serie de batallas y de muertes en que se resume la historia de varias décadas del siglo XIX de los dos lados del Plata. Una historia entreverada " como los tientos de un lazo", dice Borges en su « Milonga para los orientales » (1965). 
en la confusión que en el período de formación de ambos países genera la asociación del color rojo con los federales del lado argentino y con los unitarios del lado uruguayo y su contraparte (la simétrica asociación del color blanco con los unitarios del lado argentino y con los federales del lado uruguayo), Borges se complace en proponer variaciones de la misma historia, situándola a veces del lado argentino y a veces del lado uruguayo. La idea de que poco importa si se está hablando de batallas argentinas o uruguayas se repite en una estrofa de la milonga citada :

¿Quién dirá de quiénes fueron

Esas lanzas enemigas

Que irá desgastando el tiempo,

Si de Ramírez o Artigas?

eso en otra estrofa de esa misma milonga, Borges se complace en evocar un episodio en el que se mezclan uruguayos y argentinos y en el que lucha Rafael Hernández, el hermano del autor del Martín Fierro :

Milonga de la milonga

A la sombra del ombú,

Milonga del otro Hernández

Que se batió en Paysandú.

Hay aquí una alusión a la batalla de Paysandú y a la acción heroica de Rafael Hernández, federal argentino que luchó junto a los blancos orientales contra las tropas coloradas de Venancio Flores, apoyadas por los brasileños en el inicio de lo que sería luego la guerra de la Triple Alianza.

Borges se refiere en su Autobiografía (1970) a la batalla argentina de La Verde, que tuvo lugar en 1874 y en la que fueron derrotadas las fuerzas del general Mitre, figura asociada al campo unitario en la época de Rosas, ya que vivió en el exilio en Uruguay. En esa batalla (que tuvo lugar en el norte de la provincia de Buenos Aires) murió, luchando en las tropas mitristas, el abuelo paterno de Borges, que había nacido en Montevideo. El coronel Borges « envuelto en un poncho blanco [...] avanzó hacia las líneas enemigas, donde lo alcanzaron dos balas de Remington ».

33 Una escena muy similar a la que Borges recuerda en esa autobiografía de 1970 había aparecido ya en « La otra muerte » (El aleph, 1949) cuando el doctor Juan Francisco Amaro evocaba, frente al coronel Dionisio Tabares, lo que éste todavía no recordaba (y después recordaría) : la actuación de Pedro Damián, personaje que había nacido en Entre Ríos, en la batalla de Masoller, en Uruguay, cerca de la frontera con Brasil. Téngase en cuenta que la batalla real de Masoller tuvo lugar en1904 y que concluyó la guerra civil entre blancos y colorados uruguayos. He aquí la versión del doctor Amaro :

En la cumbre de la cuchilla se había hecho fuerte la infantería colorada; los nuestros cargaron, a lanza ; Damián iba en la punta, gritando, y una bala lo acertó en pleno pecho. Se paró en los estribos, concluyó el grito y rodó por tierra y quedó entre las patas de los caballos. Estaba muerto y la última carga de Masoller le pasó por encima.

La escena repite en realidad, no en su desenlace pero sí en su núcleo, lo que los historiadores y la memoria colectiva retienen de la acción del líder blanco Aparicio Saravia durante aquella batalla: dicen que Saravia, vestido con poncho y sombrero blanco, salió a recorrer las primeras líneas para estimular a sus soldados y que fue herido, con lo cual se precipitó la derrota definitiva de los blancos. Saravia no murió en la batalla sino en la cama, después de diez días de agonía, pero constatamos que la historia de Pedro Damián repite por un lado la del abuelo de Borges y, por otro, la de Saravia. Y poco 
importa que en un caso la batalla se haya producido del lado argentino y que el poncho blanco haya sido entonces un símbolo unitario y que en el otro caso la batalla haya tenido lugar del lado uruguayo, donde el blanco fue el emblema de la lucha federal. Cuando se piensa en estos deslizamientos, no resulta casual que el doctor Amaro recuerde el grito de ¡Viva Urquiza! proferido por Pedro Damián antes de morir y que el coronel Dionisio Tabares observe, lacónicamente :

- No como si peleara en Masoller, sino en Cagancha o India Muerta, hará un siglo.

La elección de estas dos batallas entre muchas otras es también significativa: la de Cagancha fue una batalla perdida en 1839 por los blancos uruguayos, que lucharon a las órdenes de Pedro Echagüe y de Juan Antonio Lavalleja (militares enviados por Juan Manuel de Rosas para apoyar al ex presidente blanco Manuel Oribe contra las fuerzas el líder colorado Fructuoso Rivera) ; en cambio el desenlace de la batalla de India Muerta fue el contrario, ya que fue ganada por los blancos en 1845 y significó la derrota definitiva del líder colorado Fructuoso Rivera. En ambas participó el general argentino Justo José de Urquiza y eso explica la mención de ese nombre en el cuento de Borges, pero salvo para un especialista de la historia uruguaya, el sentido político y los contextos de todas estas batallas se confunden. En el cuento de Borges saltamos de la derrota blanca de Masoller a la evocación de la pasada derrota blanca de Cagancha y a la pasada derrota colorada de India Muerta, y todas estas derrotas del lado uruguayo repiten en realidad la del abuelo de Borges, que había nacido en Uruguay y que murió del lado argentino, luchando entre argentinos y de blanco, con un blanco que no era entonces símbolo de la ideología federal, sino color emblemático de los unitarios.

La serie no concluye aquí, sino que la misma escena vuelve en « El otro duelo " (El informe de Brodie, 1970) cuando los partidarios de Timoteo Aparicio, caudillo blanco uruguayo y líder de la revolución de las lanzas, pierden en el otoño de 1871 una batalla contra los colorados. La confusión de líderes, bandos y momentos históricos se acentúa en este cuento, ya que el narrador elige designar al líder sólo por su apellido (Aparicio), con lo cual el lector de Borges confunde al personaje con el Aparicio Saravia de Masoller, figura que, como nos lo recuerda Daniel Balderston, para ese entonces ya había aparecido asociada muchas veces al criollismo en la obra de Borges, por ejemplo en 1925 en « Queja de un criollo », luego en "Historia de jinetes » (1954 y en la segunda edición de Evaristo Carriego, 1955), en el poema "Los gauchos » de Elogio de la sombra (1969) y, más tarde, en "Avelino Arredondo » (1975) (Balderston 2000, p. 79-82).

Entreverada y confusa es entonces la larga serie de batallas de las guerras civiles del siglo XIX que Borges recrea a lo largo de toda su obra, y difícil es definir los bandos y situar con certeza los escenarios en una $u$ otra orilla del Plata.

\section{El Uruguay como tierra de prodigios discretos}

Si las diferencias se borronean cuando se trata de contar episodios de la historia de la formación del estado uruguayo y del estado argentino, el matiz parece volver a acentuarse cuando Borges practica el género fantástico. Uruguay aparece entonces como un lugar propicio para los prodigios discretos, aquellos que, como es habitual en el género, llevan al lector a cuestionar los marcos sociocognitivos con los que normalmente se explica el mundo. Es lo que ocurre en "Tlön, Uqbar, Orbis Tertius », en "Funes el memorioso " (ambos en Ficciones, 1944, aunque hubo versiones anteriores ${ }^{11}$ ). La tierra 
oriental parece también un lugar favorable a ciertos experimentos en que lo totalizante puede confundirse con lo totalitario. Y el ejemplo aquí vuelve a ser "Tlön... » y, más tarde, el cuento « El congreso » (aparecido en 1971 y reeditado en El libro de arena, en 1975).

El narrador de « Tlön, Uqbar, Orbis Tertius » declara haber escrito la primera parte de su texto en la ciudad de Salto Oriental en 1940 y agrega una «posdata de 1947 » (que obviamente sorprende al lector cuando éste la lee en las primeras ediciones del cuento ${ }^{12}$ ). En esta posdata se revela que en Uruguay, en Cuchilla Negra, cerca de la frontera con Brasil, al norte de Tacuarembó, hubo en los años 40 un misionero de la secta tlönista «que venía de la frontera ». El personaje es descrito como un «vecino invisible » que no deja dormir a los que se alojan en la pulpería porque alterna "denuestos inextricables » con « rachas de una sola milonga». A la madrugada el misterioso extranjero aparece muerto, pero el narrador, que viaja con Amorim (recordemos que Enrique Amorim es el marido de la prima de Borges, Esther Haedo), descubre entre sus cosas « un cono de metal reluciente del diámetro de un dado » que los hombres apenas pueden levantar, ya que su peso es « intolerable » y provoca « una impresión desagradable de asco y de miedo ». El narrador deduce que se trata de uno de los hrönir descritos en la enciclopedia de Tlön, objetos producidos por la mente humana que han comenzado a invadir el mundo, y supone que en ese caso particular el cono es imagen de la divinidad de ciertas religiones de Tlön. En las páginas siguientes el lector se entera de que la estrategia tlönista ha cambiado para volverse más eficaz y que por eso se ha eliminado, o por lo menos se ha atenuado, la multiplicación de los hrönir. Con todo, queda claro que cuando hubo que elegir un punto del planeta para poner discretamente en práctica sus métodos, la orilla oriental del Plata pareció ser el lugar adecuado para quienes pretendían convertirse en los amos del planeta.

Otro prodigio discreto que también tiene lugar en Uruguay es el que presenta « Funes el memorioso ». El incipit del cuento se detiene en la diferencia entre los habitantes de ambas orillas. El uruguayo -dice el narrador- tiende al ditirambo para hablar de sus compatriotas y lo hace porque se siente orgulloso de lo que es, mientras que el argentino ( (e deplorable condición ») es literato, cajetilla, porteño, palabras que los uruguayos piensan, aunque no las digan, cuando se encuentran con argentinos pretenciosos y convencidos de su propio saber. Irineo Funes fue un compadrito de Fray Bentos que siempre tuvo el increíble don de poder decir la hora sin necesidad de mirar el reloj y que cuando se cayó de un caballo adquirió una memoria y sobre todo una capacidad de percepción sobrenaturales. La acumulación de percepciones y recuerdos hizo que la vida de Funes se volviera intolerable y que, haciendo honor a su apellido (y menos honor a su nombre), el joven muriera de una congestión pulmonar cuando tenía apenas veintiún años. Uruguay conserva y resguarda la memoria del prodigio; sus poetas (entre ellos Pedro Leandro Ipuche) reservan un enfático elogio al «Zarathustra cimarrón y vernáculo » de Fray Bentos. Sin dejar de apoyar el homenaje, el narrador de "Funes el memorioso", deplorable argentino, se permite reflexionar acerca de las « incurables limitaciones» de Irineo, prodigiosamente memorioso, pero al mismo tiempo incapaz de muchas cosas, por ejemplo de dormir o simplemente de pensar.

Otro caso en que el Uruguay se perfila como el escenario favorable para un proyecto, si no prodigioso por lo menos sorprendente, es el que plantea el cuento «El congreso». El proyecto en cuestión no es ni más ni menos que un «Congreso del Mundo » y el lugar previsto para la reunión es La Caledonia, estancia que Alejandro Glencoe posee en 
Uruguay, en la zona de la frontera con Brasil, y en la que comienzan a realizarse las obras necesarias para el gran evento. Sin embargo, las obras se interrumpen porque se decide que el congreso no se hará, o al menos no del modo en que se había imaginado, es decir no en La Caledonia. Esto no significa en absoluto que el congreso no exista. Según sugiere el narrador, el congreso existe desde siempre :

La empresa que hemos acometido es tan vasta que abarca -ahora lo sé- el mundo entero. No es unos cuantos charlatanes que aturden en los galpones de una estancia perdida. El Congreso del Mundo comenzó con el primer instante del mundo y proseguirá cuando seamos polvo. No hay un lugar en que no esté. El Congreso es los libros que hemos quemado. El Congreso es los caledonios que derrotaron a las legiones de los Césares. El Congreso es Job en el muladar y Cristo en la cruz.

$42 \mathrm{Al}$ leer estas líneas el lector de Borges piensa inmediatamente en la lotería de Babilonia, en las galerías hexagonales de la biblioteca de Babel o en el proyecto de Tlön, con su lenta, metódica y subterránea remodelación de la realidad. La particularidad del Congreso, aunque luego se diluya en la indiferenciación de la totalidad, es que cuando hubo que pensar en convocarlo en algún punto del planeta, Borges lo imaginó en una estancia uruguaya, cerca de la frontera con Brasil. Esto confirma la imagen del Uruguay como tierra de prodigios discretos.

\section{¿Un refugio para traidores?}

Uruguay, y más precisamente la región que linda con Brasil, aparece en otros cuentos como un refugio para traidores. Así resulta ser en « La forma de la espada » (incluido en Ficciones) y en «El muerto » (incluido en El Aleph). Vincent Moon, traidor a la causa irlandesa, se instala en una estancia en Tacuarembó. Es «el Inglés de la Colorada». Balderston define la frontera norte en la literatura de Borges como ese «lugar de pasaje donde se pierde la identidad y puede construirse otra, lugar de ambigüedad en la lengua y en la moral, lugar de peligro y violencia », observa acertadamente que « ese nombre de la estancia, la Colorada, incluye indudablemente una referencia implícita a las guerras civiles uruguayas " y argumenta que como en el campo uruguayo el partido dominante fue el blanco, «de haber sido colorado el dueño de la estancia, eso habría sido muy evidente en la región » (Balderston, 2000, p. 78 y p. 88).

Así como el apelativo « inglés » oculta y a la vez revela la verdadera identidad de Moon (se trata de un irlandés que se comportó como un verdadero inglés, es decir que traicionó la causa irlandesa), así también una estancia « colorada » en medio de un campo "blanco » marca una rareza. Una línea secreta parece vincular a la estatua de Kilpatrick en la cima de un cerro gris rodeado de ciénagas rojas («Tema del traidor y del héroe ») con este « inglés » de bigote gris y cara cruzada por « una cicatriz cenicienta » que domina en los campos « empastados » de una estancia "Colorada », sobre todo si se tiene en cuenta que ambos fueron irlandeses y que ambos fueron traidores.

En «El muerto ", Uruguay y en particular la zona que linda con Brasil, es de nuevo la tierra que acoge al que anda huyendo de la justicia y que parece prestarse al cambio de identidades y a la traición. Otálora es argentino, pero huye de su tierra porque ha matado a un hombre. Después de una "travesía tormentosa y crujiente», el joven llega a Montevideo. Allí conoce a Azevedo Bandeira y empieza a trabajar para él junto a otros contrabandistas uruguayos. Pero Otálora es ambicioso y engreído : 
Lo mueve la ambición y también una oscura fidelidad. Que el hombre (piensa) acabe de entender que yo valgo más que todos sus orientales.

Hacia el final del cuento, Otálora se ha hecho amigo del guardaespaldas de Bandeira, dirige a los contrabandistas y aspira a usurpar el lugar del gran jefe. La zona de operaciones en la que se mueve "parece conspirar con él y apresura los hechos ». Sin embargo, el desenlace del cuento le demostrará que si la tierra uruguaya oculta, también castiga. En el momento de morir Otálora comprenderá que su aparente ascenso no fue más que una concesión que los uruguayos otorgaron a quien consideraban, desde hacía mucho tiempo, muerto.

Escondite de traidores entonces, ma non troppo, puesto que todos acaban por ser desenmascarados : Vincent Moon se ve obligado a confesar su verdadera identidad al final del relato y Otálora comprende, en el momento de morir, que él no valía más que los orientales, que la posibilidad de cambiar de identidad cruzando el río es menos cierta de lo que a primera vista parece. La tierra uruguaya acaba instaurando su propia justicia, no necesariamente institucional y pública, pero inexorable y tal vez más auténtica.

\section{A modo de conclusión}

Borges concluye su « Milonga para los orientales » (1965) con el deseo de que Uruguay y Argentina vuelvan a ser un único país :

Milonga para que el tiempo

Vaya borrando fronteras;

por algo tienen los mismos

Colores las dos banderas.

Como en su autobiografía, como en sus ensayos sobre el criollismo, como en su recreación de la interminable serie de guerras civiles que llevaron de las declaraciones de independencia al nacimiento del estado moderno, Borges imagina que el tiempo (que aquí es uno solo y que avanza en Buenos Aires y en Montevideo con idéntico ritmo) puede borrar las diferencias entre uno y otro margen del Plata. El lector de Borges sabe, sin embargo, que el otro y el mismo, como lo advertía Borges en el inicio de Fervor de Buenos Aires, son "nadas [que] en poco difieren" y que en el revés de esta voluntad de indiferenciación vuelven a dibujarse los matices de una historia que seguirá contándose.

\section{BIBLIOGRAFÍA}

Balderston, Daniel, « Gauchos y gaúchos. Excursiones a la frontera uruguayo-brasileira », en su Borges : realidades y simulacros, Buenos Aires, Biblos, 2000, p. 77-93.

Barone, Orlando (compilador), Diálogos Borges/Sabato, Buenos Aires, Emecé Editores, 2007. Puede consultarse en : http://www.fcaglp.unlp.edu.ar/ sixto/sabato/dialogos/dialogos.htm Blanco, Mercedes, « Arqueologías de Tlön. Borges y el Urn Burial de Browne », en : Variaciones Borges № 15, Aarhus, 2003, p. 19-46. 
Borges, Jorge Luis, Fervor de Buenos Aires, 1923. Edición consultada : Borges, Jorge Luis, Obras completas, Buenos Aires, Emecé, 1974.

Borges, Jorge Luis, Luna de enfrente, 1925. Edición consultada: Borges, Jorge Luis, Obras completas, Buenos Aires, Emecé, 1974.

Borges, Jorge Luis, Inquisiciones, 1925. Edición consultada : Madrid, Alianza Editorial, 1998.

Borges, Jorge Luis, El tamaño de mi esperanza, 1926. Edición consultada : Madrid, Alianza Editorial, 1998.

Borges, Jorge Luis, « Palabras finales (Prólogo, breve y discutidor) », en : Pereda Valdés, Ildefonso, Antología de la moderna poesía uruguaya (1900-1927), Buenos Aires, El Ateneo, 1927, p. 219-221.

También en : Borges, Jorge Luis, Textos recobrados 1919-1929, Buenos Aires, Emecé, 1997, p. 330-331.

Borges, Jorge Luis, Ficciones, 1944. Edición consultada : Borges, Jorge Luis, Obras completas, Buenos Aires, Emecé, 1974.

Borges, Jorge Luis, El Aleph, 1949. Edición consultada : Borges, Jorge Luis, Obras completas, Buenos Aires, Emecé, 1974.

Borges, Jorge Luis, El Hacedor, 1960. Edición consultada : Borges, Jorge Luis, Obras completas, Buenos Aires, Emecé, 1974.

Borges, Jorge Luis, Para las seis cuerdas, 1965. Edición consultada : Borges, Jorge Luis, Obras completas, Buenos Aires, Emecé, 1974.

Borges, Jorge Luis, An autobiographical essay, edición en inglés en : The New Yorker, New York, 19 de septiembre de 1970. Edición en español : Autobiografía, Buenos, Aires, El Ateneo, 1999.

Borges, Jorge Luis, El informe de Brodie, 1970. Edición consultada : Borges, Jorge Luis, Obras completas, Buenos Aires, Emecé, 1974.

Borges, Jorge Luis, El libro de arena, 1975. Edición consultada : Borges, Jorge Luis, Obras completas 1975-1985, Buenos Aires, Emecé, 1989.

Laborde, Gustavo, « El costado oriental de Borges », 1999, consultable en : http://www.oei.org.co/ sii/entrega26/art05.htm

Larre Borges, Ana María, « Memoria oriental de Borges », Brecha, 20-VIII-1999, cit. en Carolina Porley, « Espejismos », Brecha 17/8/2012, consultable en :

http://www.brecha.com.uy/index.php/politica-uruguaya/398-espejismos

Rodriguez Monegal, Emir, « El olvidado ultraísmo uruguayo », en : Revista Iberoamericana, no 118-119, enero-junio 1982, p. 257-274.

\section{NOTAS}

1. E. Rodriguez Monegal, «El olvidado ultraísmo uruguayo", en: Revista Iberoamericana, nº 118-119, enero-junio 1982, p. 257-274.

2. D. Balderston, Borges: realidades y simulacros, Buenos Aires, Biblos, 2000, p. 77-93.

3. A. M. Larre Borges, « Memoria oriental de Borges », Brecha, 20-VIII-1999, cit. en Carolina Porley , «Espejismos», Brecha 17/8/2012, consultable en: http://www.brecha.com.uy/index.php/ politica-uruguaya/398-espejismos

4. J. L. Borges, An autobiographical essay, edición en inglés en The New Yorker, New York, 19 de septiembre de 1970.

5. Edición en español: Autobiografía, Buenos, Aires, El Ateneo, 1999, p. 17. 
6. Ibid., p. 17.

7. Reflexión de Borges evocada por G. Laborde (corresponsal del Servicio Informativo Iberoamericano de la OEI, Montevideo, Uruguay) en «El costado oriental de Borges », 1999, consultable en : http://www.oei.org.co/sii/entrega26/art05.htm

8. J. L. Borges, « Palabras finales (Prólogo, breve y discutidor) », en : I. Pereda Valdés, Antología de la moderna poesía uruguaya (1900-1927), Buenos Aires, El Ateneo, 1927, p. 219-221. También en : J. L. Borges, Textos recobrados 1919-1929, Buenos Aires, Emecé, 1997, p. 330-331.

9. Borges también evoca este episodio en el comienzo de "In memoriam J.F.K. », en El hacedor (1960).

10. O. Barone (compilador), Diálogos Borges/Sabato, Buenos Aires, Emecé Editores, 2007. La cita puede leerse en : http://www.fcaglp.unlp.edu.ar/ sixto/sabato/dialogos/dialogos.htm

11. "Tlön... » fue publicado en 1940 en la revista Sur y ese mismo año en la Antología de la literatura fantástica, luego en 1941 en El jardín de senderos que se bifurcan en 1941 y finalmente en Ficciones en 1944 ; «Funes » fue publicado en 1942 en La Nación y luego en Ficciones en 1944.

12. Según Mercedes Blanco, es posible pero innecesario buscar un significado alegórico para este « escribir desde el porvenir ». Cabe sin duda pensar, argumenta Blanco, teniendo en cuenta lo que estaba pasando en Europa en 1940, que el narrador pudiera imaginar que en 1947 la barbarie habría ganado la batalla y que por eso decidiera situar en esa fecha la descripción del avance totalitario de Tlön. Sin embargo, agrega Blanco, la migración de objetos entre diferentes tiempos, además de responder a la lógica tlönista, respeta perfectamente las convenciones de la literatura fantástica. M. Blanco, «Arqueologías de Tlön. Borges y el Urn Burial de Browne », en : Variaciones Borges № 15, Aarhus, 2003, p. 19-46.

\section{RESÚMENES}

La imagen del Uruguay en la obra de Jorge Luis Borges se declina en tenues matices. El escritor oscila, en efecto, entre la tendencia a borrar las diferencias entre las dos orillas del Plata y la tendencia a subrayarlas. Los matices se diluyen en la definición del criollismo (en los ensayos de Borges) y en la recreación (en sus cuentos) de las guerras civiles que marcaron el proceso de formación del estado moderno en Argentina y en Uruguay. Los matices entre ambas orillas se subrayan, en cambio, en muchos otros textos en los que la banda oriental del río aparece como una tierra más dramática, más elemental y más brava que la Argentina, o como un espacio en el que el tiempo transcurre más lentamente, o como un escenario propicio para los prodigios discretos, o como una zona fronteriza de refugio, tan precario como peligroso, para traidores de toda laya.

The image of Uruguay in Jorge Luis Borges's works expresses itself in tenuous shades. The writer oscillates between a tendency to erase and a tendency to emphasize differences between the two banks of the Plata river. Shades fade when Borges defines the criollo element (in his essays) and when he rewrites (in his short stories) the history of the period during which Argentine and Uruguayan nation-states emerged by and through warfare. Shades between the two banks of the Plata river reappear, in contrast, in many other texts. The eastern bank becomes then a more dramatic, more basic and braver country than Argentina, a place where time passes more slowly, a space for quiet wonder, or a border where all kinds of traitors can certainly find a place of refuge, but a place that will turn out to be as precarious as dangerous. 
L'image de l'Uruguay dans l'œuvre de Jorge Luis Borges se décline en de multiples nuances. L'écrivain oscille, en effet, entre la tendance à effacer les différences entre les deux rives du Río de la Plata et la tendance à les souligner. Les nuances s'estompent dans la définition du sentiment criollo (dans les essais de Borges) et dans l'évocation poétique (dans ses contes) des guerres civiles qui jalonnent le processus de formation de l'état moderne en Argentine et en Uruguay. En revanche, les nuances entre les deux rives sont souvent soulignées ailleurs. La rive orientale du Plata devient alors une terre plus dramatique, plus élémentaire et plus courageuse que l'Argentine, un espace où le temps passe moins vite, un contexte favorable aux prodiges discrets, une zone frontalière où toutes sortes de traitres peuvent trouver un refuge aussi précaire que dangereux.

ÍNDICE

Mots-clés: Borges, image, Uruguay, Argentine, sentiment criollo, frontière, prodige, guerres civiles, littérature des gauchos, rives du Rio de la Plata

Palabras claves: imagen, criollismo, frontera, prodigio, guerras civiles, gauchesca, márgenes del Río de la Plata

Keywords: Argentina, criollo element, border, wonder, civil wars, gaucho literature, the banks of the Plata river

\section{AUTOR}

\section{GRACIELA VILLANUEVA}

Université Paris-Est Créteil, CREER/Imager (EA3958) 